\title{
Branding Spin-off Scholarly Journals: Transmuting Symbolic Capital into Economic Capital*
}

Mahdi Khelfaoui (khelfaoui.mahdi@uqam.ca)

Yves Gingras (gingras.yves@uqam.ca)

* This paper was published in Journal of Scholarly Publishing. To cite the paper: Khelfaoui, M. and Y. Gingras. (2020). Branding Spin-Off Scholarly Journals: Transmuting Symbolic Capital into Economic Capital. Journal of Scholarly Publishing, vol. 52, no. 1, pp. 1-19.

\begin{abstract}
In this paper, we analyze a relatively recent commercial strategy used by large academic publishers to capitalize on the brand names of their most prestigious scientific journals. Using Pierre Bourdieu's model of capital conversion, we explain how publishers transfer the symbolic capital of an already prestigious journal to derivative journals that share in the prestige of the original brand and transform it into new economic capital. As shown by their high impact factors, these newly created journals benefit from the name recognition and reputation of the originals after which they are named. Plus, through a manuscript routing mechanism, the publishers recycle some of the submissions rejected by their highly selective flagship journals by redirecting manuscripts with their reviews to lower-impact journals on their list that may decide to publish them for an article processing charge.
\end{abstract}

Keywords: scholarly journals, branding, symbolic capital, economic capital, academic publishers, manuscript transfer mechanisms

\section{Introduction}

After the end of World War II, the economics of academic journal publishing was radically transformed into an international oligopoly dominated by a handful of giant publishers. ${ }^{1}$ Their commercial control of academic journals, especially scientific, technical, and medical journals, has continued through the transition of the publishing industry in the digital era. In 2013, only five publishers (Elsevier, Wiley-Blackwell, Springer, Taylor \& Francis, and Sage) accounted for more than 50 per cent of published papers in all scientific disciplines. ${ }^{2}$ This fundamental transformation of the economics of academic publishing had major consequences for the circulation of knowledge inside and outside scientific communities, especially those located in poor and developing countries. As a consequence of this concentration, the academic institutions that employ scientists 
have to pay huge amounts of money to access the scientific knowledge that the scientists in their employ produce. Most of the profits accrue to the publishers.

While the consequences of what can be considered a form of privatized scientific knowledge have been well documented, ${ }^{3}$ in this paper we want to focus our attention on a relatively recent commercial strategy by which publishers leverage the branding of their most prestigious scientific journals. In addition to being vehicles of knowledge, scholarly journals have become important economic assets owned by private companies. Publishers have realized that, in addition to profiting from traditional subscription and licensing fees, they can build on their most prestigious titles to translate prestige into more profit. In the terms of sociologist Pierre Bourdieu, the publishers turn a specific form of capital, namely, the symbolic capital of their high-profile publications, into economic capital. ${ }^{4}$ Bourdieu's model of the relations between economic, social, cultural, and symbolic capital is thus useful for shedding light on the recent trend of multiplying the journal titles derived from prestigious parent journals such as Nature, Science, or The Lancet.

Instead of just creating new journals from scratch that would have to construct their credibility over time and thus accumulate symbolic capital, publishers can use an already prestigious brand and extend its value through derivative journals that keep visible the link to the symbolic value of the existing brand. This constitutes a new manner of extracting additional economic value from a small number of existing journals. Being associated with the parent publication by name, these new journals are likely to be welcomed by researchers, who will then pressure their academic institutions to subscribe to them.

Successful branding depends on transferring from parent publication to daughters the cachet accumulated over the parent's publication history. The more a journal is recognized as a prestigious venue and benefits from having an international readership, the easier it will be for its publisher to sell subscriptions for derivative journals to university libraries and research institutes. Publishing papers in reputed top-tier journals has become a sine qua non for scholars wanting to land an academic position, win a promotion, or get funding for their research project. ${ }^{5}$ New journals related by name to prestigious titles have a greater likelihood of gaining recognition as a desirable publishing outlet than do publications that are entirely new. Trying to maximize their visibility in 
their field, scientists may choose to submit papers to these derived journals in the belief that, through a kind of 'halo effect,' the new journals bear a portion of their parent's prestige.

\section{The Reuse of Prestigious Publication Names}

The transfer of symbolic capital from an original title to its spin-offs happens through a naming strategy whereby a prestigious name is included in the names of the new journals. The kinship between the derivatives and the original journal is made visually even more obvious to the reader in the cover design of the branded journals, which mimic the original one (same fonts and graphic design). In addition to the well-known Nature, there are now Nature Chemistry, Nature Physics, Nature Microbiology, Nature Ecology and Evolution, etc. Likewise, The Lancet has its own derivatives in The Lancet Oncology, The Lancet Neurology, The Lancet Rheumatology, etc. The eponymic relation between the derivatives and their parent journal allows them, as we will show, to attain high impact factors in very short periods of time. Thus, they appear to be attractive venues for scientific researchers, who are nowadays being evaluated by their academic institutions more and more on the basis of the impact factors of the journals in which they publish their papers and not on the inherent value of their papers or on the number of citations those papers have attracted. ${ }^{6}$ These quantitative evaluation standards have, moreover, been internalized by early-career researchers, who consider them to be part of the rules of the academic game. ${ }^{7}$

Of course, there are several past examples of renowned scientific journals that have given birth to a family of journals bearing the original name. For instance, in 1970, the American Physical Society's flagship journal, Physical Review, was split into four journals, Physical Review A, B, C, and D. Another example is Studies in the History and Philosophy of Science, which was divided into parts $A, B$, and $C$ in 1998 . These changes, however, were less motivated by commercial goals than by the increasing fragmentation of scientific disciplines into different specialties, as well as a general rapid growth of scientific research and publications, which made it difficult for a single journal to handle increasingly diverse and specialized topics and to handle a continuous increase in article submissions. ${ }^{8}$ 
Moreover, journal title changes are not rare and can be motivated by several factors, such as a change in scope, geographic coverage, audience, language, or frequency of publication. ${ }^{9}$ The particular form of derivative journal creation that we analyze here is, we think, quite different in nature and related to marketing practices first developed for consumer goods, where a company constructs the brand of its new products around an original trademark that is already well known and popular among consumers. For instance, the famous food product multinational Nestlé created a series of products named after its original trademark (Nesquick, Nestea, Nespresso, and Nescafé). ${ }^{10}$

\section{The Symbolic Capital of Scholarly Journals}

As members of a scientific community, researchers strive to gain recognition, that is, accumulate symbolic capital, in their field through making discoveries, winning prizes for the originality of their publications, being cited, or some other form of academic achievement that can bring them recognition from their peers. ${ }^{11}$ Like researchers and scientific institutions, scientific journals can also accumulate symbolic capital, and researchers tend to submit their papers to the journals they consider the most prestigious in their fields. There thus exists, in any discipline or sub-discipline, an implicit hierarchy of journals known to scientists through their reading and interactions with their peers. For instance, PNAS (Proceedings of the National Academy of Sciences of the United States of America) and Proceedings of the Royal Society $A$ and $B$ derive most of their good reputation from the fact that they are the official journals of the National Academy of Sciences and the Royal Society of London. The longevity of a title can also add to its credit, as does of course a history of publishing articles considered to be seminal or revolutionary. The journal hierarchy in a discipline does vary over time. In physics, for instance, Annalen der Physik was the most prestigious at the beginning of the twentieth century and published the revolutionary papers of Max Planck and Albert Einstein and contributions by many future Nobel Prize-winning physicists. After the 1930s, the prestige of Physical Review, an American journal created in 1893, came to surpass Annalen der Physik and remains today the most central journal of the discipline. ${ }^{12}$ 
The symbolic hierarchy of journals can be measured using a proxy like the wellknown Journal Impact Factor (JIF), which happens to correlate well with the perceived prestige of journals. As a consequence, the value of the symbolic goods produced by researchers in the form of scientific articles now tends to be associated with the prestige of the journals in which they are published, despite the fact that the visibility of the papers, as measured by the number of citations received, can be much less than what the JIF might lead one to expect the citation count to be. ${ }^{13}$ A journal's reputation does enhance, however, the probability that a paper will be cited, independently of its 'quality.' This 'Matthew effect' was first analyzed by the sociologist Robert K. Merton, who pointed out that some scientists received more recognition than they may deserve simply because they were already recognized. ${ }^{14}$ Scientific journals are also beneficiaries of the Matthew effect. ${ }^{15}$

\section{A Trend toward Proliferating Daughter Journals Named after a Prestigious Parent} Understanding the symbolic hierarchy of journals, academic publishers have recently found a way to extract more value from their portfolio of journals by selecting the most prestigious titles and creating derivative journals that extend the original brand. It all started with Nature but was repeated by the competing generalist journal Science as well as by medical, biological, and chemical journals: The Lancet, Journal of the American Medical Association, British Medical Journal, Cell, and Journal of the American Chemical Society.

Created in 1869 as a weekly scientific magazine, Nature has been published by the London publishing house Macmillan for more than a century. In 1995, German media giant Holtzbrinck bought 71 per cent of Nature's publisher Macmillan and completed its

purchase in 1999. That same year, Nature Research, then known as the Nature Publishing Group, was created from the merger of Stockton Press and Macmillan Magazines. In 2015, Holtzbrinck and Nature Research merged with another giant publisher, Springer, leading to the creation of the giant Springer Nature.

In 1992, Macmillan launched Nature's first derivative journal, Nature Genetics. Over the following two decades (from 1992 to 2011), eighteen Nature-branded research titles were created. Figure 1 shows that this first wave of new journals was followed by 
five years of rest, a period of time perhaps used to observe the effects of these creations. A new period of growth began in 2015 with the creation of sixteen new branded journals in the following five years, consisting of about three new titles per year. The accelerated pace of creating Nature-branded journals since 2015 coincided with the merger of Nature Publishing Group with Springer that same year, indicating that a more aggressive journalbranding strategy for the Nature trademark was initiated by the giant publisher after the flagship journal came under its umbrella. In 2000, a year following its creation, Nature Publishing Group also started a suite of Nature Reviews journals, which concentrate on publishing synthetic literature reviews instead of original research articles. Fifteen such Nature Reviews were launched between 2000 and 2005. After the merger with Springer, six additional journals were added between 2015 and 2021, for a total of twenty-one Nature Reviews-branded journals. As shown in Figure 1, Nature's strategy of derived journals was original, and its success may have led large publishers of other prestigious scientific journals to adopt the same strategy.

The Lancet is, along with the New England Journal of Medicine, among the most respected generalist medical journals and also a venerable institution (published since 1823). The journal was sold by the Lancet Publishing Group to Elsevier in 1991. Between 2000 and 2020, the giant private publisher created eighteen specialized Lancetbranded journals. Three derived journals (The Lancet Oncology, The Lancet Infectious Diseases, and The Lancet Neurology) were created between 2000 and 2002. Then, starting in 2012, a new wave began, and fifteen new titles were added. The latest in the Lancet family, The Lancet Regional Health, was launched in 2020, and it is itself divided into six sub-journals covering different geographic areas of the world. Two other broadcoverage medical journals have followed the same strategy: the British Medical Journal created twenty-four BMJ-branded journals beginning in 2008 and its competitor the American Medical Association, publisher of the Journal of the American Medical Association (JAMA), followed suit with twelve new JAMA-branded journals starting in 2013.

The American Chemical Society (ACS), a private non-profit organization, is the most important chemical society in the world with 157,000 members. It is also among the top-five academic publishers in the natural sciences, with more than eighty chemistry- 
related journals. The ACS is widely known for publishing, since 1879, its flagship journal, the Journal of the American Chemical Association (JACS). ${ }^{16}$ In 2006, building on its institutional prestige and that of JACS, it launched its first ACS-branded journal, ACS Chemical Biology. Since then, twenty-four other ACS-branded journals have followed in succession, at a pace of approximately three new journals per year since 2014. ACS-branded journals explore, with a chemical lens, various scientific and technological subfields such as energy, electronics, photonics, materials, earth and space, and biology and medicine, thus extending the range of topics covered by the portfolio of ACS journals, which were previously mainly focused on the traditional sub-disciplines of chemistry (physical chemistry, organic chemistry, biological chemistry, and engineering chemistry).

Cell, a journal covering multiple specialties of biology, is also considered among the most prestigious titles in its field. Established by British geneticist Benjamin Lewin in 1974, Cell was published by the MIT Press until 1986, when Lewin bought the rights of the journal to publish it under its own private structure, Cell Press. The first Cell-branded journal, Molecular Cell, was launched in 1998, a year before the acquisition of Cell Press by Elsevier, which added five new derived titles between 1999 and 2007. Since 2012, five other titles have joined the Cell family, for a total of eleven. Finally, Science, property of the non-profit American Association for the Advancement of Science, has also followed the branding trend by creating four Science-related titles since 2007, after it had launched its first one (Science Signaling) in 1999. Overall, Figure 1 shows that the branding trend for prestigious journals accelerated considerably after 2012. Fifty-seven branded journals were launched from 1992 to 2012; that count rose to ninety-three in the years since. 


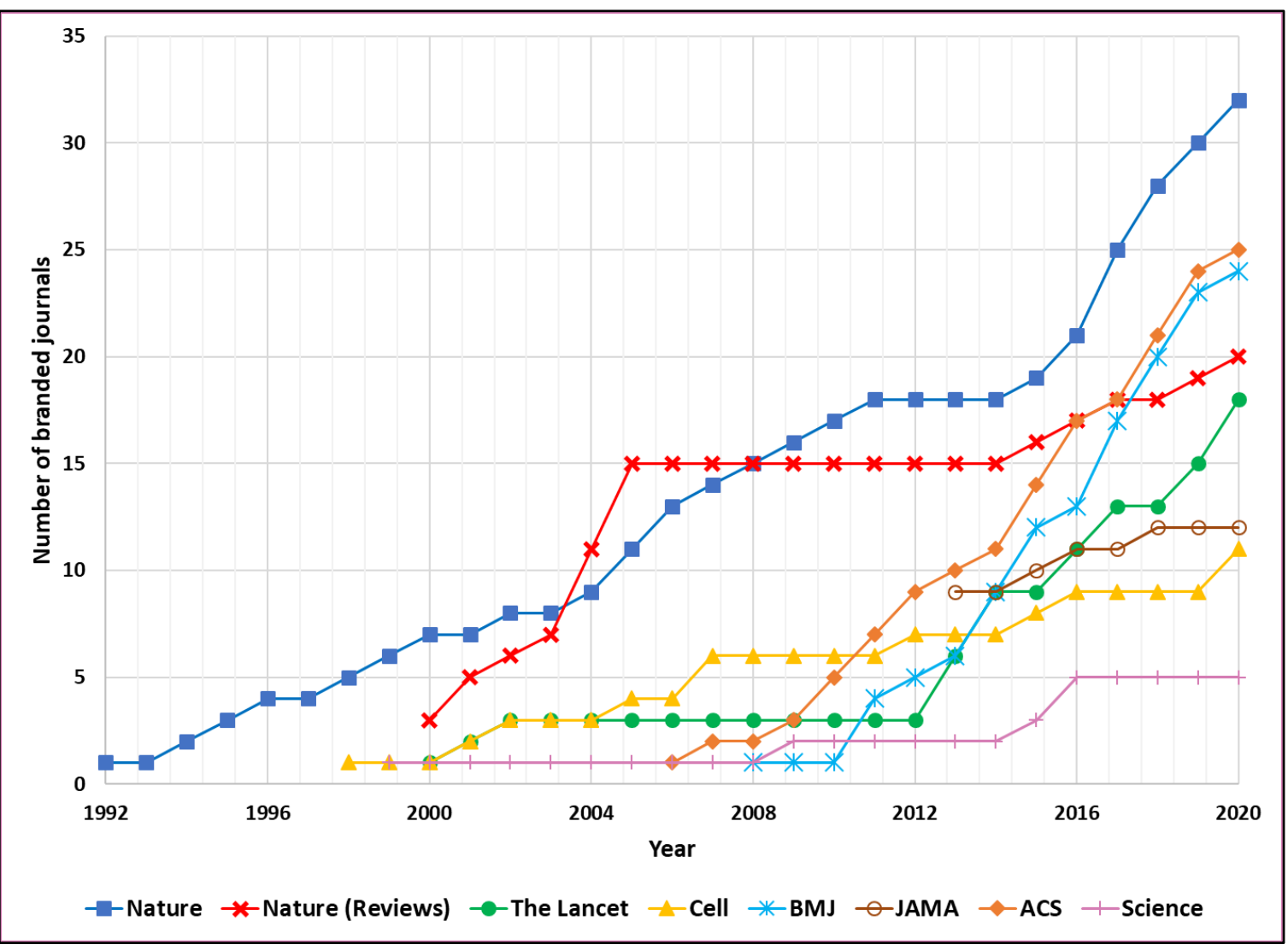

Figure 1. Trend in the number of branded journals derived from a prestigious parent.

\section{Inheriting the Prestige of the Parent Journal}

To get an idea of the rapidity with which the new journals gain recognition from the scientific communities they target, we can look at their rankings in their disciplines as measured by Clarivate Analytics' JIF. Using the 2019 Journals Citation Report (JCR), we find that thirty-two journals branded as Nature or Nature Reviews, six Lancet-branded journals, four Cell-branded journals, two JAMA-branded journals, and two Sciencebranded journals are ranked among the top-100 journals, all disciplines combined. Thus, 46 per cent of the top-100 journals, ranked according to JIF in the 2019 JCR, all disciplines combined, are branded titles. Moreover, all twenty-eight Nature-branded research journals with a JIF, all eighteen Lancet-branded journals, eleven out of twelve $J A M A$-branded journals, and three out of five Science-branded journals were ranked in the top-ten of their scientific specialties in 2019. As shown in Table 1, all branded journals associated with Nature, Lancet, JAMA, and Science that were launched between 
2015 and 2018 already ranked in the top-five or top-ten journals of their respective fields according to the 2019 JCR. Most branded journals associated with Cell and ACS that were launched between 2015 and 2018 were ranked between the sixteenth and forty-third positions.

Table 1. 2019 JCR ranks of recently launched derivatives of prestigious journals (20152018)

\begin{tabular}{|l|l|l|l|}
\hline Journal Title & Launched & Subject Category & $\begin{array}{l}\text { 2019 JCR } \\
\text { Rank }\end{array}$ \\
\hline Nature Plants & 2015 & Plant science & 3 \\
\hline Nature Energy & 2016 & Energy \& fuels & 1 \\
\hline Nature Microbiology & 2016 & Microbiology & 4 \\
\hline Nature Astronomy & 2017 & Astronomy \& astrophysics & 4 \\
\hline Nature Biomed. Engineering & 2017 & Biomedical engineering & 1 \\
\hline Nature Ecology \& Evolution & 2017 & Evolutionary biology & 3 \\
\hline Nature Human Behaviour & 2017 & Neurosciences & 11 \\
\hline Nature Catalysis & 2018 & Physical chemistry & 2 \\
\hline Nature Electronics & 2018 & Engineering, electrical \& electronic & 1 \\
\hline Nature Sustainability & 2018 & Environmental studies & 1 \\
\hline Lancet Gastro. \& Hepatol. & 2016 & Gastroenterology \& hepatology & 5 \\
\hline Lancet Public Health & 2016 & Public, environmental health & 2 \\
\hline $\begin{array}{l}\text { Lancet Child \& Adolesc. } \\
\text { Health }\end{array}$ & 2017 & Pediatrics & 2 \\
\hline Science Advances & 2015 & Multidisciplinary & \\
\hline Science Robotics & 2016 & Robotics & 4 \\
\hline Science Immunology & 2016 & Immunology & 1 \\
\hline Cell Systems & 2015 & Cell biology & 7 \\
\hline ACS Central Science & 2015 & Multidisciplinary & 27 \\
\hline ACS Infectious Diseases & 2015 & Infectious diseases & 16 \\
\hline ACS Energy Letters & 2016 & Energy \& fuels & 16 \\
\hline ACS Sensors & 2016 & Nanoscience \& nanotechnology & 24 \\
\hline ACS Earth and Space Chem. & 2017 & Geochemistry \& geophysics & 21 \\
\hline ACS Applied Bio Materials & 2018 & Biomedical engineering & 43 \\
\hline ACS Applied Energy Mater. & 2018 & Energy \& fuels & 39 \\
\hline & & & 6 \\
\hline
\end{tabular}

The high rankings obtained by recently launched branded journals confirm that the transfer of symbolic capital from the original journals to their derivatives takes place in a short period of time. For instance, according the $J C R$, all Nature-branded journals (except the most recent ones that are still waiting to be ranked) were among the top ten, 
and mostly top five, of their subject categories as soon as they were assigned a JIF and have since kept these rankings. Publishers even use these 'performances' to promote their newly created journals. For instance, in 2016, just two years after the launch of ACS Photonics, the ACS issued a press release on its website touting its publications' JIFs: New ACS journals that were eligible for review by Thomson Reuters for the first time received strongly competitive inaugural Impact Factors, illustrating the value ACS adds to the dissemination of quality research in new or emerging fields of science. ACS Photonics achieved an impressive Impact Factor of 5.404, ranking as one of the top 10 journals in the Optics category. ${ }^{17}$

The American Medical Association's JAMA provides a striking example of how branding can be a powerful tool for transferring prestige from a parent journal to its derivatives. JAMA is considered one of the most prestigious generalist titles in the field of medicine. The American Medical Association also publishes highly respected specialized journals in medicine, some of which date back to the beginning of the twentieth century. In 2013, the association started building what it called the JAMA Network of journals. Nine were launched in 2013, and by 2020 there were twelve journals in the JAMA Network.

However, in contrast to other publishers who created entirely new journals, the American Medical Association renamed nine existing titles in its portfolio using the JAMA brand. Thus, the suite of existing journals named on model of Archives of (e.g., Archives of Psychiatry and Archives of Dermatology) became JAMA followed by the name of the specialty: JAMA Psychiatry and JAMA Dermatology. This variation on the derivative journal strategy provides us with a kind of 'natural experiment' in which to measure the effect of branding on the visibility of already existing journals, since we can compare their prestige before and after their titles were renamed with the JAMA brand. We use the measure of their changing ranking in the $J C R$. While some journals were already highly ranked in their medical specialty and have kept similar positions after being knighted JAMA (e.g., JAMA Internal Medicine and JAMA Ophthalmology), Figure 2 shows that the rebranding strategy had a striking effect on five JAMA-branded journals. Within a few years after their renaming, these journals all improved in their rankings, reaching or nearing the top rank in their specialties, which shows that their rebranding not only resulted in attracting more high-quality papers but probably also in generating more 
citations from authors, who are influenced in their citations practices by the prestige of the cited journal. Interestingly, such a positive impact of rebranding is not observed for standard journals that change their names. In those cases, one can even observe a decline in ranking, since it usually takes some years for authors to recognize a title change and start citing the journal with its new name. ${ }^{18}$

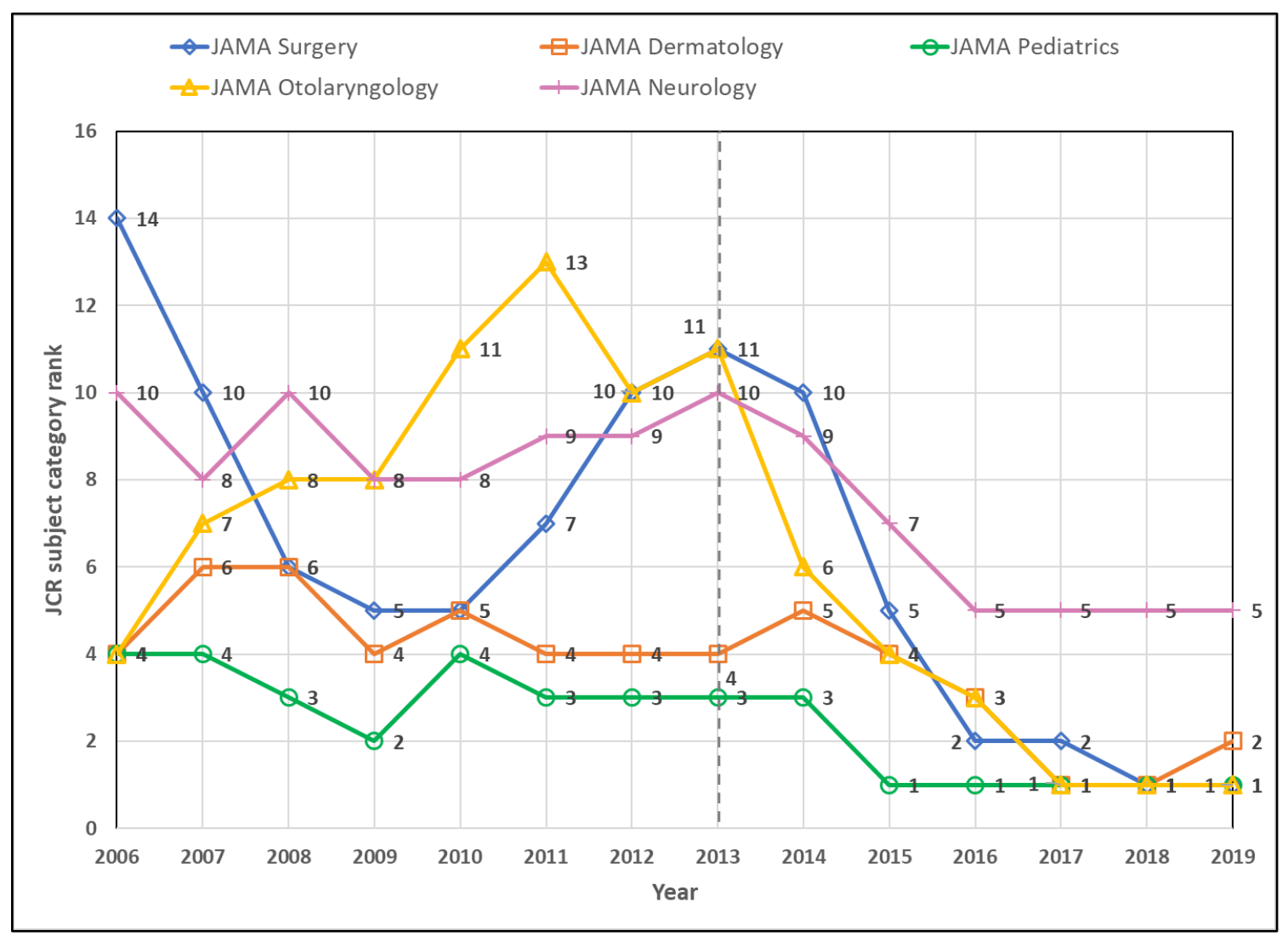

Figure 2. Trend for five $J A M A$-branded journals $J C R$ ranks (2006-2019). The dashed line marks the year of renaming with the JAMA brand. The declining lines after 2013 indicate movement toward the highest rank (number one) in their specialty.

\section{Redirecting Rejected Papers to Less Prestigious Journals of the Same Publisher}

Prestigious journals such as those analyzed in this paper are known for their very high standards of selectivity, since they reject about 90 per cent of papers submitted. For instance, 80 per cent of papers sent to Nature are desk-rejected and do not even go through peer review. The Lancet and JAMA have acceptance rates of only 5 per cent and 6 per cent. Prestigious journals usually receive a high number of submissions: 
approximately 10,000 for Nature and Science each year, and JAMA received 7400 in 2019. A good portion of these rejected papers are still considered by these publishers to be of interest. They are often rejected only because they do not address 'hot topics' or simply because of space limitations. Publishers do not necessarily want to 'waste' these papers by pushing them to journals owned by rival publishers, especially papers for which the company has invested some resources through the peer review process. Consequently, a way to monetize them is to ask their authors to redirect the submission to derivative journals or to other less selective open access journals owned by the same publisher. This proposition is attractive since the original reviewers' reports are used by the second-choice journal, which accelerates the new reviewing and editing process. ${ }^{19}$

Through this process, articles rejected by prestigious journals but recycled in less visible (and often open access) journals from the same publisher are thus still moneymakers. Manuscript-transfer options are offered to authors by all publishers discussed in this paper. In the case of Science, authors can select a transfer destination even before first submitting to the journal. On the Scirev.org website, which gathers authors' experiences of peer review in various scientific journals, a scientist posted a rejection letter from Science that describes a manuscript transfer option from Science to Science Advances, which is published in open access since 2015 and applies article processing charges (APCs) of US $\$ 4500$ :

During submission, you requested transfer to Science Advances should Science decide not to proceed with your manuscript. We are pleased that you are choosing to transfer to our high-level, interdisciplinary, open access journal. Please use the link below to confirm the transfer. ${ }^{20}$

In March 2018, Elsevier's Cell Press launched an interdisciplinary open access journal called iScience (note the similarity to Science), which charges a US\$3000 APC. For its first year of operation, iScience received 59 per cent of its submissions through manuscript transfers from other Elsevier journals. ${ }^{21}$ One can suppose these transfers came in part from Cell Press's more prestigious titles, including Cell-branded journals and other high-standing Cell Press titles from different disciplines, such as Chem, Med, Immunity, or Joule. In collaboration with Cell Press, Elsevier also set up a transfer mechanism from any Cell Press or Lancet-branded journal to another new open access 
journal, EBioMedicine. The journal's website informs authors who have submitted papers to Lancet- or Cell-branded journals that they could 'receive a decision that includes an invitation to move [their] submission to EBioMedicine,' which charges a US\$3200 APC. ACS has also set up a manuscript transfer mechanism from its journal with the highest symbolic capital, JACS, to its specialized ACS-branded journals. The British Medical Journal Publishing Group and the American Medical Association have done the same thing with their flagship medical journals and their spin-off branded titles.

The manuscript-transfer mechanism rests on the symbolic hierarchy of branded journals owned by a given publisher. It is well illustrated by a pyramidal structure shown by a Nature Research marketing team during a promotional presentation. ${ }^{22}$ Nature, with the highest symbolic capital of its family of journals, is at the top of the pyramid. Manuscripts that are rejected by Nature can be transferred to the second level of the pyramid, represented by the Nature-branded research journals, which, although less prestigious than the original, are still attractive venues with high impact factors and low acceptance rates, often below 10 per cent. At the third level of the pyramid, the multidisciplinary open access Nature Communications, with a $\$ 5380$ APC, is another alternative for manuscript transfers. It is less selective than Nature and the other Naturebranded research journals, with an acceptance rate of 50 per cent. At the bottom level of the pyramid, Scientific Reports, Nature Research's open access mega-journal, an equivalent and competitor to PLOS One, is the last transfer option. It has a $\$ 1870$ APC and 75 per cent acceptance rate. The farther down the pyramid an author goes, the less prestigious the journals become, and the author must pay to be published. Note also that the APC also diminishes with the symbolic capital of the journal, as could be expected from Bourdieu's model of the relationship between symbolic and economic capital.

\section{The Partner Journals Series: Selling Symbolic Capital to Academic Institutions}

In 2014, Nature Research started the Nature Partner Journals (NPJ) series. This commercial initiative is a new derived brand of Nature open access journals in partnership with academic institutions, research non-profit organizations, philanthropic foundations, or membership associations. This brand is recognizable by the addition of 
the initials npj before the subject-specific title of the journals (for example: npj Quantum Information, npj Breast Cancer, npj Precision Oncology). As shown in Table 2, since 2014, Nature Research has launched twenty-four open access and independently peerreviewed npj journals. NPJ partners, or rather customers, can benefit from several services, including 'access to a dedicated publishing team that oversees daily journal activities, providing guidance and publishing insights to maximize exposure for both [the partner institution] and [the] journal.' In addition, Nature Research's editorial office offers to manage the peer review process and handle the typesetting, copy-editing, and proofing of articles. Finally, it also provides 'strategic support on areas including manuscript transfer and content commissioning. ${ }^{23}$ Thus, npj journals constitute another level of the manuscript-transfer pyramid from more to less prestigious journals of the Nature journals family.

Table 2. Twenty-four Nature Research partner journals and the partnering institutions

\begin{tabular}{|l|l|l|l|}
\hline Nature partner journal & Launched & Partner institution & Country \\
\hline npj Primary Care Respirat. Medicine & 2014 & Primary Care Respiratory Society & UK \\
\hline npj Quantum Information & 2015 & University of New South Wales & Australia \\
\hline npj Biofilms and Microbiomes & 2015 & Nanyang Technological University & China \\
\hline npj Computational Materials & 2015 & Shanghai Institute of Ceramics & China \\
\hline npj Aging \& Mechanisms of Disease & 2015 & Jap. Society of Anti-Aging Medicine & Japan \\
\hline npj Breast Cancer & 2015 & Breast Cancer Research Foundation & USA \\
\hline npj Systems Biology \&Applications & 2015 & Systems Biology Institute & USA \\
\hline npj Microgravity & 2015 & NASA & USA \\
\hline npj Schizophrenia & 2015 & Schizophrenia Int. Research Society & USA \\
\hline$n p j$ Parkinson's Disease & 2015 & Parkinson's Foundation & USA \\
\hline$n p j$ Regenerative Medicine & 2016 & Monash University & Australia \\
\hline$n p j$ Science of Learning & 2016 & University of Quensland & Australia \\
\hline npj Quantum Materials & 2016 & Nanjing University & China \\
\hline$n p j$ Genomic Medicine & 2016 & King Abdulaziz University & Saudi Arabia \\
\hline$n p j$ Vaccines & 2016 & University of Texas Medical Branch & USA \\
\hline$n p j$ Flexible Electronics & 2017 & Nanjing Tech University & China \\
\hline$n p j$ Materials Degradation & 2017 & University of Sci. and Tech. Beijing & China \\
\hline$n p j$ Science of Food & 2017 & Beijing Tech. and Business University & China \\
\hline$n p j$ 2d Materials and Applications & 2017 & FCT da Universidade Nova de Lisboa & Portugal \\
\hline$n p j$ Precision Oncology & 2017 & University of Minnesota & USA \\
\hline$n p j$ Clean Water & 2018 & King Fahd University & Saudi Arabia \\
\hline$n p j$ Climate \& Atmospheric Science & 2018 & King Abdulaziz University & Saudi Arabia \\
\hline$n p j$ Digital Medicine & 2018 & Seoul Nat. Univ. Bundang Hospital & South Korea \\
\hline$n p j$ Urban Sustainability & 2020 & RMIT University & Australia \\
\hline
\end{tabular}


In exchange for paying for these services, the partner institutions benefit from having a scientific journal with the symbolically attractive Nature trademark that does not give the impression of coming from the institution itself. As one might expect, this venture does not tend to attract the most well-known institutions, which do not need such symbolic boosting. It may however attract institutions in search of such recognition and which also have the economic resources to buy some symbolic capital by association. As shown in Table 2, many of the academic partnerships with NPJ come from countries actively working to raise their international scientific profile. China comes first with six partnerships, followed by Australia with four partnerships and Saudi Arabia with three partnerships; Saudi Arabia is known to entice highly visible scientists to accept 'affiliations' to their universities, thus boosting the universities' positions in international academic rankings. ${ }^{24}$ Although seven partner institutions are based in the United States, five of them are non-profit organizations or philanthropic foundations rather than universities. From the perspective of Nature Research, npj-branded journals could be considered a second- or even third-class category of assets next to the Nature-branded journals. The npj journals' APCs vary between US\$2500 and US\$3500 per research article. Most of the npj journals are ranked in the first quartile, between the tenth and fifty-sixth positions of their JCR subject categories, with some of them ranking even higher. This suggests that, although diluted in the npj initials, Nature's symbolic capital is still transferred to some degree to the $n p j$-branded journals.

In 2018, the American Association for the Advancement of Science (AAAS) launched its own Science Partner Journals program with the open access journal Research, thus joining the trend established four years earlier by Nature Research. AAAS's Research journal is a partnership with its Chinese equivalent, the China Association of Science and Technology. Since then, six other open access, electroniconly Science Partner Journals publications have been launched, all of them through partnerships with Chinese universities or research institutions. In the Science Partner Journals program, the AAAS acts as a 'contractual publisher and service provider for that partner organization ... providing editorial training, platform access, and marketing services.' Since the partner institutions remain 'editorially independent and responsible for the content published in each journal, ${ }^{25}$ the AAAS seems to let its symbolic capital 
be used by the partner in exchange for economic value. A similar strategy of trying to be associated with a prestigious organization was used by the Bank of Sweden when it created in 1968 its Prize in Economic Sciences in Honor of Alfred Nobel and asked the Nobel Foundation to manage the operations, thus giving the erroneous perception that there was indeed a 'Nobel Prize in Economics' and that this discipline was thus on a par with physics, chemistry, or physiology and medicine, the only sciences awarded a Nobel Prize and whose winners are often considered by the media and the general public to be geniuses in their disciplines. ${ }^{26}$

\section{Conclusion}

Scholarly publishing in the sciences is marked by a concentration of many journals owned by a small number of large commercial conglomerates. One of the strategies these publishers use to maximize profits from their journals is take the most prestigious journals in their collection and create a family of derived publications that bear the prestigious parent's name. This strategy lets publishers extract more revenues by spreading the symbolic capital of the parent publication across the family of derivatives. These publishers have also found a way to keep submissions in house by redirecting worthy submissions rejected by the prestige journal to the less selective, but still quite profitable, open access derivatives in their catalogue. This system of manuscript transfer benefits from the pressure put on researchers by their institutional employers to maximize the number of papers published in outlets with high JIFs.

Scientific researchers are both the producers and the consumers of these journals' content, so a good strategy for the publisher is to offer researchers diverse services to facilitate the writing of their papers. Publishers nowadays not only publish scientific papers written by scientists but also offer scientists seminars on how to write papers, where to submit them to maximize their visibility, and how to write a good research grant. Even the process of evaluation is part of the global strategy of publishers. The Nature Index, created in 2014, ranks an institution according to the number of papers its faculty have published in the Nature Research group's journals. ${ }^{27}$ In this way, Nature Research subtly encourages researchers and their institutions to try publishing in a journal of its group in order to improve their ranking. 
In the end, major publishers exercise much control over scientific knowledge production, while those who perform the valuable work of editors, reviewers, and authors mostly do so without pay. Despite the apparent irrationality of a system that diverts economic resources away from investing directly in research, the system has endured because individual scientists believe they can themselves transform the symbolic capital of their best papers into economic capital through getting grants or better academic positions. This seems to create a win-win situation from the point of view of the individual scientist, although it appears dysfunctional at the level of the research system, as shown by the systemic problems confronting academic libraries that have struggled to afford the escalating costs of scientific journal subscriptions since the latter 1990s. ${ }^{28}$

\footnotetext{
${ }^{1}$ Carol Tenopir and Donald King, 'Trends in Scientific Scholarly Journal Publishing in the United States,' Journal of Scholarly Publishing 28, no. 3 (1997): 135-70.

${ }^{2}$ Vincent Larivière, Stefanie Haustein, and Philippe Mongeon, 'The Oligopoly of Academic Publishers,' PLOS One, 10 June 2015, e0127502.

${ }^{3}$ Fei Shu et al., 'Is It Such a Big Deal? On the Cost of Journal Use in the Digital Era,' College \& Research Libraries 79, no. 6 (2018): 785-98; Carol Tenopir and Donald W. King, Towards Electronic Journals: Realities for Scientists, Librarians, and Publishers (Washington DC: SLA Publishing, 2000).

${ }^{4}$ Pierre Bourdieu, 'The Forms of Capital,' in Handbook of Theory and Research for the Sociology of Education, ed. John Richardson (New York: Greenwood, 1986), 241-58.

${ }^{5}$ Yves Gingras, 'The Transformation of the Scientific Paper: From Knowledge to Accounting Unit,' in Gaming the Metrics: Misconduct and Manipulation in Academic Research, ed. Mario Biagioli and Alexandra Lippman (Cambridge, MA: MIT Press, 2020), 43-55.
} 
${ }^{6}$ Yves Gingras, Bibliometrics and Research Evaluation: Uses and Abuses (Cambridge, MA: MIT Press, 2016).

${ }^{7}$ David Nicholas et. al., 'Early-Career Researchers' Quest for Academic Reputation in the Digital Age,' Journal of Scholarly Publishing 49, no. 4 (2018): 375-96.

${ }^{8}$ David Kaiser, 'Booms, Busts, and the World of Ideas: Enrollment Pressures and the Challenge of Specialization,' Osiris 27, no. 1 (2012): 276-302.

${ }^{9}$ Mavis B. Molto, 'Characteristics of Serial Title Changes and Recognition of New Serial Works: Theoretical and Practical Implications,' Serials Review 37, no. 4 (2011): 275-89. ${ }^{10}$ Éric Delattre, 'Le succès des marques dérivées,' Annales des mines (June 1999): 7075.

${ }^{11}$ Warren Hagstrom, The Scientific Community (New York: Basic Books, 1965); Pierre Bourdieu, 'The Specificity of the Scientific Field and the Social Conditions for the Progress of Reason,' Social Science Information 14, no. 6 (1976): 19-47.

${ }^{12}$ Mahdi Khelfaoui and Yves Gingras, 'Physical Review: From the Periphery to the Center of Physics,' Physics in Perspective 21, no. 1 (2019): 23-42.

${ }^{13}$ Manolis Antonoyiakinnis, 'Impact Factor Volatility Due to a Single Paper: A Comprehensive Analysis,' Quantitative Science Studies 1, no. 2 (2020): 639-63.

${ }^{14}$ Robert K. Merton, 'The Matthew Effect in Science,' Science 158, no. 3810 (1968): 5663.

${ }^{15}$ Vincent Larivière and Yves Gingras, 'The Impact Factor's Matthew Effect: A Natural Experiment in Bibliometrics,' Journal of the American Society for Information Science and Technology 61, no. 2 (2010): 424-27. 
${ }^{16}$ Marianne Noel, 'La construction de la valeur économique d'une revue en chimie. Le cas du Journal of the American Chemical Society (1879-2010),' Revue française des sciences de l'information et de la communication 11 (2017), https://doi.org/10.4000/rfsic.3281.

${ }^{17}$ ACS press release, 14 June 2016, https://www.acs.org/content/acs/en/pressroom/newsreleases/2016/june/acs-journals-areagain-among-the-most-cited-in-chemistry-flagship-journal-achieves-best-impact-factorever.html.

${ }^{18}$ David Tempest, 'The Effect of Journal Title Changes on Impact Factors,' Learned Publishing 18, no. 1 (2005): 57-62.

${ }^{19}$ See, for instance, authors guideline on Science's website: https://www.sciencemag.org/authors/science-information-authors.

${ }^{20}$ Letter from the editors of Science to the authors reproduced here: https://scirev.org/reviews/science/.

${ }^{21}$ Information available here: https://www.elsevier.com/connect/editors-update/helpingauthors-find-the-best-home-for-their-article.

${ }^{22}$ See http://eisz.mtak.hu/images/2016_infonapok/prez/0519_SpringerNature_Editorial.pdf.

${ }^{23}$ See the description of the NPJ program on Nature's website: https://www.nature.com/nature-research/open-access/nature-partner-journals. ${ }^{24}$ Yves Gingras, 'How to Boost Your University up the Rankings,' University World News, 18 July 2014, https://www.universityworldnews.com/post.php?story=20140715142345754. 
${ }^{25}$ See Science's website: https://spj.sciencemag.org/become-partner/.

${ }^{26}$ Yves Gingras, 'Beautiful Mind, Non-existent Prize: The Bank of Sweden Prize in Economic Sciences,' in Real World Economics: A Post-autistic Economics Reader, ed. Edward Fullbrook (London: Anthem Press, 2007), 71-75.

${ }^{27}$ Yves Gingras, Bibliometrics and Research Evaluation, 50.

${ }^{28}$ Glenn S. McGuigan and Robert D. Russell, 'The Business of Academic Publishing: A Strategic Analysis of the Academic Journal Publishing Industry and Its Impact on the Future of Scholarly Publishing,' Electronic Journal of Academic and Special Librarianship 9, no. 3 (2008), https://digitalcommons.unl.edu/ejasljournal/105/. 